\title{
Gas-Phase Conformations of Cationized Poly(styrene) Oligomers
}

\author{
Jennifer Gidden and Michael T. Bowers \\ Department of Chemistry and Biochemistry, University of California, Santa Barbara, USA \\ Anthony T. Jackson and James H. Scrivens \\ ICI Research and Technology Centre, Wilton, Middlesbrough, Cleveland, United Kingdom
}

\begin{abstract}
The gas-phase conformations of poly(styrene) oligomers cationized by $\mathrm{Li}^{+}, \mathrm{Na}^{+}, \mathrm{Cu}^{+}$, and $\mathrm{Ag}^{+}\left(\mathrm{M}^{+} \mathrm{PSn}\right)$ were examined using ion mobility experiments and molecular mechanics/ dynamics calculations. $\mathrm{M}^{+} \mathrm{PS} n$ ions were formed by MALDI and their ion-He collision cross-sections were measured by ion mobility methods. The experimental collision crosssections of each $\mathrm{M}^{+} \mathrm{PS} n$-mer were similar for all four metal cations and increased linearly with $n$. Molecular modeling of selected $\mathrm{M}^{+} \mathrm{PS}$ oligomers cationized by $\mathrm{Li}^{+}$and $\mathrm{Na}^{+}$yielded quasi-linear structures with the metal cation sandwiched between two phenyl groups. The relative energies of the structures were $\sim 2-3 \mathrm{kcal} / \mathrm{mol}$ more stable when the metal cation was sandwiched near the middle of the oligomer chain than when it was near the ends of the oligomer. The cross-sections of these theoretical structures agree well with the experimental values with deviations typically around $1-2 \%$. The calculations also show that the metal cation tends to align the phenyl groups on the same side of the $-\mathrm{CH}_{2}-\mathrm{CH}-$ backbone. Calculations on neutral poly(styrene), on the other hand, showed structures in which the phenyl groups were more randomly positioned about the oligomer backbone. The conformations and metal-oligomer binding energies of $\mathrm{M}^{+} \mathrm{PS}$ are also used to help explain CID product distributions and fragmentation mechanisms of cationized PS oligomers. (J Am Soc Mass Spectrom 2002, 13, 499-505) (c) 2002 American Society for Mass Spectrometry
\end{abstract}

A lthough synthetic polymers are not generally known for their ability to be converted into gas-phase ions, an increasing number of them are now routinely analyzed by mass spectrometry $[1,2]$. One reason for this has been the continuing development of matrix-assisted laser desorption/ionization (MALDI) [3, 4] sources, perhaps the most common ionization method used for polymer analysis. Being a relatively soft ionization process, MALDI typically produces mass spectra with little fragmentation. While this is an important attribute for obtaining accurate molecular weight distributions or determining the masses of repeat units and end groups, it is not very helpful in measuring structural properties of polymers.

Tandem mass spectrometry (MS/MS) experiments, however, can provide additional information needed to determine the structures of gas-phase ions that is not readily available in single MS experiments. Using collision-induced dissociation (CID) or metastable fragmentation, the masses and intensities of fragment ions can be measured which often are characteristic of the

Published online March 27, 2002

Address reprint requests to: Michael T. Bowers, Department of Chemistry \& Biochemistry, University of California, Santa Barbara, CA 93106, USA. E-mail: bowers@chem.ucsb.edu structure of the intact, parent ion. Structures and sequences of biological polymers such as peptides [5] or nucleic acids [6] are commonly obtained from CID spectra. However, MS/MS experiments have seen limited use in the analysis of synthetic polymers.

Mass spectrometry studies of synthetic polymers usually involve time-of-flight (TOF) instruments that are not necessarily designed for MS/MS experiments. Post source decay (PSD) studies, in which fragmentation is induced by increasing the laser power during MALDI, can be performed on TOF instruments, but is limited in its mass resolution. Few PSD results have been reported for synthetic polymers [7-9]. Other methods that have been used to obtain CID or PSD spectra of synthetic polymers employed hybrid sector-TOF instruments [10-14] and Fourier transform mass spectrometers [15]. These experiments focused on obtaining information about the composition and structures of end groups and repeat units, but the spectra also showed some interesting characteristics of the fragmentation of synthetic polymers.

Two such polymer systems that were studied by MALDI-CID are poly(methyl methacrylate) (PMMA) cationized by alkali ions $[7,11]$ and poly(styrene) (PS) cationized by $\mathrm{Cu}$ and $\mathrm{Ag}[7,12,14]$ : 


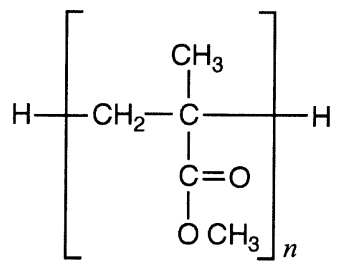

PMMA

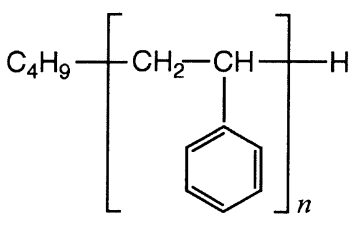

PS
These polymers do not appear to have much in common, but they have very similar CID fragmentation patterns. The CID spectra of both systems are dominated by cationized fragment ions with low mass-tocharge ratios $(\mathrm{m} / \mathrm{z})$, corresponding to the cleavage of several repeat units from each end of the oligomer.

Ion mobility experiments [16, 17] and molecular modeling of the cationized PMMA oligomers gave valuable conformational and energetic data that was used to help explain the CID product distributions and develop a possible fragmentation mechanism [18]. The results indicated that the oligomers are U-shaped with the alkali cation bound to multiple carbonyl oxygens near the ends of the oligomer (up to three from each end). The CID fragmentation was proposed to be initiated by the "opening-up" of the quasi-cyclic structures, leaving the metal cation attached to either end of the oligomer. Then, the metal cation either dissociates from the oligomer (more common for larger alkali ions such as $\mathrm{Rb}$ and $\mathrm{Cs}$ ) or it induces a cleavage of the PMMA backbone nearby.

In the study presented here, the ion mobility experiments and molecular modeling calculations were extended to the characterization of poly(styrene) oligomers cationized by $\mathrm{Cu}^{+}, \mathrm{Ag}^{+}, \mathrm{Li}^{+}$and $\mathrm{Na}^{+}$. The conformations and metal-oligomer binding properties of these systems are compared to the PMMA results and used to help explain the CID fragmentation observed for cationized poly(styrene).

\section{Experiment}

The details of the ion mobility experiments and molecular modeling calculations used in this study have been published $[19,20]$, so only a brief description will be given here. Cationized poly(styrene) ions $\left(\mathrm{M}^{+} \mathrm{PS} n, \mathrm{M}=\right.$ $\mathrm{Cu}, \mathrm{Ag}, \mathrm{Li}, \mathrm{Na}$ ) were produced in a home-built MALDI ion source [20]. Dithranol (1,8-dihydroxy-9[10H] anthracenone) was used as the matrix and tetrahydrofuran as the solvent. The matrix and polymer solutions were prepared at a concentration of $10 \mathrm{mg} / \mathrm{mL}$. Saturated solutions of $\mathrm{LiCl}, \mathrm{NaI}, \mathrm{CuCl}_{2}$, and $\mathrm{AgNO}_{3}$, dissolved in methanol or water, were used as the cationizing agents. Approximately $50 \mu \mathrm{L}$ of the metal salt (5 $\mu \mathrm{L}$ saturated solution, $45 \mu \mathrm{L}$ methanol) was applied to the sample target first and dried. $100 \mu \mathrm{L}$ of poly(styrene) $\left(\mathrm{M}_{\mathrm{w}}=780\right)$ and dithranol, mixed in a 1:10 ratio $(v / v)$, was then applied on top of the salt and dried.

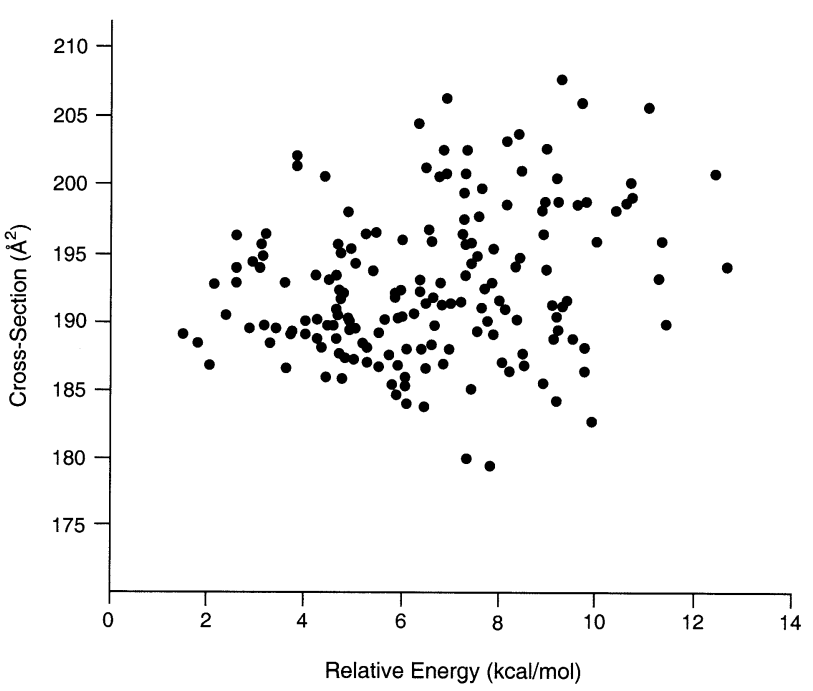

Figure 1. Scatter plot of cross-section vs. energy for the 150 theoretical structures obtained for $\mathrm{Li}^{+}$PS5. Each point in the plot represents one structure. The average cross-section of the lowest $\sim 3 \mathrm{kcal} / \mathrm{mol}$ structures was used for comparison to the experimental cross-sections.

$\mathrm{M}^{+} \mathrm{PS} n$ ions exiting the MALDI source are accelerated to $5 \mathrm{kV}$ and mass analyzed with a reverse-geometry, sector mass spectrometer. Mass spectra can be obtained at an off-axis detector by scanning the magnet. For the ion mobility experiments, the off-axis detector is disabled, and the mass-selected oligomer ion of interest (i.e., 7-mer) is decelerated to $10 \mathrm{eV}$ and injected into a drift cell [19] filled with $\sim 3$ torr of He. The ions drift through the cell under the influence of a weak electric field and are detected as a function of time, yielding an arrival time distribution (ATD). The ions' arrival times inherently contain information about their geometric shape. Compact ions, with small ion-He collision crosssections, will drift faster through the cell and arrive at shorter times than more extended ions, with larger collision cross-sections. The mobility of the ion, $K$, is accurately determined from a series of ATDs [21, 22] measured at different drift voltages $(5-25 \mathrm{~V} / \mathrm{cm})$ and, using kinetic theory [23], the ion's collision cross-section can be obtained.

Conformational information about the oligomer ions is obtained by comparing the experimental cross-sections to the cross-sections of theoretical structures. The AMBER [24] molecular mechanics/dynamics program was used to generate the candidate structures. An annealing/energy minimization cycle that has given reliable structures for several synthetic polymers [18, 25-27] was used to produce 100-150 low energy structures of selected $\mathrm{M}^{+} \mathrm{PS} n$ oligomers. The angle-averaged collision cross-section of each structure was then calculated with a previously developed projection model [20, $22,28]$. A "scatter plot" of cross-section versus energy for the 150 theoretical structures obtained for $\mathrm{Li}^{+}$PS5 is given in Figure 1. The cross-sections of the lowest $\sim 3$ $\mathrm{kcal} / \mathrm{mol}$ set of structures, which typically have only minor conformational differences, are averaged and 
a) $\mathrm{Ag}^{+} \mathrm{PS}$

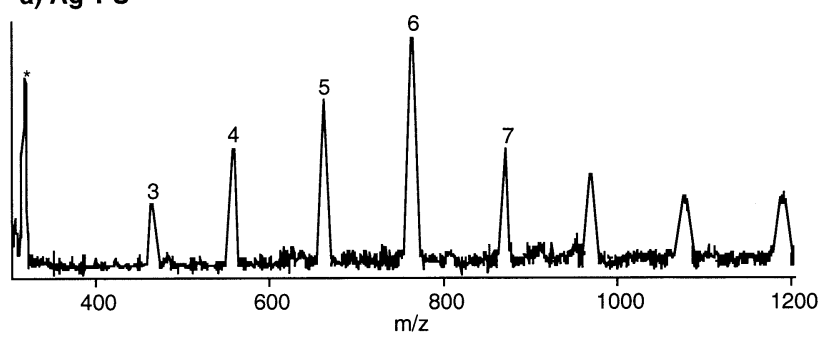

b) $\mathrm{Na}^{+} \mathrm{PS}$

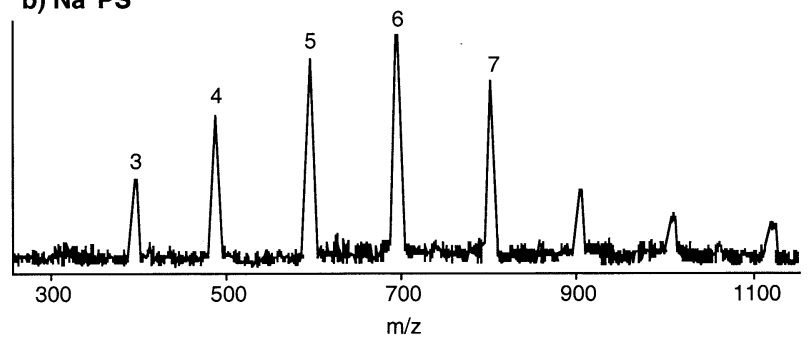

Figure 2. MALDI mass spectra of poly(styrene) 780 cationized by (a) silver and (b) sodium. The oligomers selected for the ion mobility experiments are labeled with their number of repeat units, $n$. The peak labeled with an asterisk in (a) is due to the matrix.

compared to those obtained from the ion mobility experiments.

\section{Results/Discussion}

\section{Ion Mobility Experiments}

Most mass spectrometry studies of synthetic polymers involve cationization rather than protonation. Alkali metals are usually used as the cationizing agents, but in the case of poly(styrene), $\mathrm{Ag}^{+}$or $\mathrm{Cu}^{+}$is used because they tend to yield better signals than alkali ions. However, the molecular mechanics calculations are not parameterized for transition metals, only alkali metals. Therefore, the ion mobility experiments were performed on PS oligomers cationized by $\mathrm{Li}^{+}$and $\mathrm{Na}^{+}$for comparison to theory and by $\mathrm{Cu}^{+}$and $\mathrm{Ag}^{+}$to determine whether the metal-oligomer interactions are similar for alkali metals and transition metals.

MALDI mass spectra of poly(styrene) $\left(\mathrm{M}_{\mathrm{w}}=780\right)$ doped with $\mathrm{AgNO}_{3}$ and $\mathrm{NaI}$, obtained before the drift cell, are shown in Figures $2 a$ and $2 b$. The series of peaks observed in the spectra are due to the attachment of one $\mathrm{Ag}^{+}$or $\mathrm{Na}^{+}$cation to the poly(styrene) oligomers $\left(\mathrm{M}^{+} \mathrm{PS} n\right)$. Similar distributions of $\mathrm{M}^{+} \mathrm{PS} n$ peaks are observed for both metals (once the difference in mass of the metal cation is considered). This can indicate one of two things. First, the binding energies of $\mathrm{Ag}^{+}$and $\mathrm{Na}^{+}$ to various sized PS oligomers are large enough that unimolecular loss of metal cation, which can dramatically alter the molecular weight distributions of polymers $[29,30]$, is not a significant problem. Second, the $\mathrm{M}^{+}$-PS binding energies of $\mathrm{Na}^{+}$and $\mathrm{Ag}^{+}$are similar enough that loss of metal is an equivalent problem for

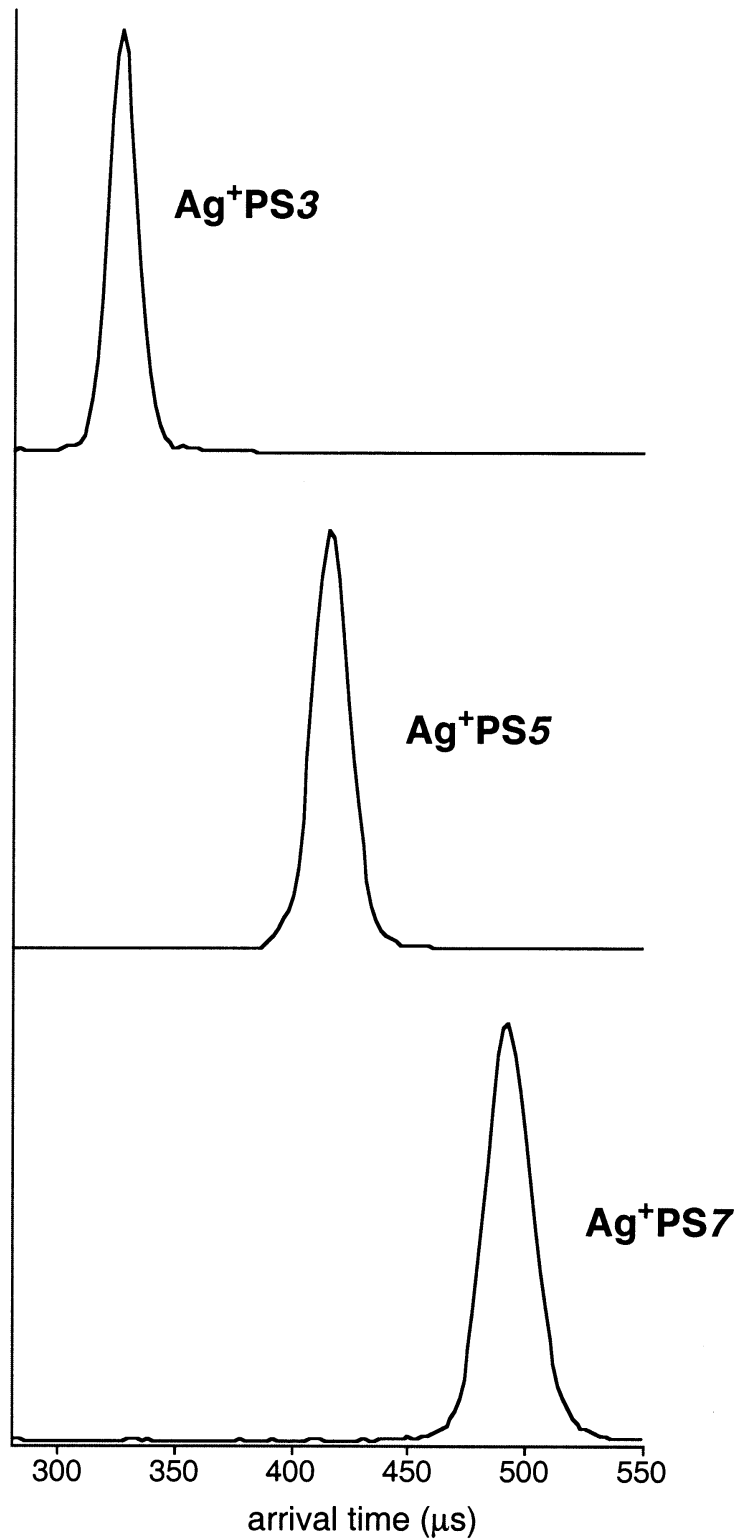

Figure 3. Arrival time distributions (ATDs) measured for the poly(styrene) 3-mer, 5-mer, and 7-mer cationized by silver at 300 K. Single peaks are observed for all $\mathrm{M}^{+} \mathrm{PS} n$ ions at all temperatures studied. A longer arrival time indicates a larger ion-He collision cross-section.

both metals. Regardless, the metal-PS interaction does not seem to be strongly dependent on whether the metal is a transition metal or alkali metal. The $\mathrm{M}^{+} \mathrm{PS}$ oligomers selected for the ion mobility experiments and molecular modeling calculations are labeled with their number of PS repeat units, $n$. The peak labeled with an asterisk in the $\mathrm{Ag}^{+} \mathrm{PS}$ spectrum is due to the matrix.

The ion mobility experiments were performed on the cationized 3-mer to 7-mer $\left(\mathrm{M}^{+} \mathrm{PS} 3\right.$ to $\left.\mathrm{M}^{+} \mathrm{PS} 7\right)$ for $\mathrm{Cu}^{+}$, $\mathrm{Ag}^{+}, \mathrm{Li}^{+}$, and $\mathrm{Na}^{+}$. Typical arrival time distributions (ATDs) are shown in Figure 3 using $\mathrm{Ag}^{+} \mathrm{PS} 3 \mathrm{Ag}^{+} \mathrm{PS} 5$, and $\mathrm{Ag}^{+} \mathrm{PS} 7$ as examples. The ATDs were obtained at a cell temperature of $300 \mathrm{~K}$ and drift voltage of $23 \mathrm{~V} / \mathrm{cm}$. The average arrival time increases with the chain length 
Table 1. Experimental and theoretical cross-sections $\left(\AA^{2}\right)$ of $\mathrm{M}^{+} \mathrm{PS} n$

\begin{tabular}{|c|c|c|c|c|c|c|}
\hline \multirow[b]{2}{*}{$n$} & \multirow{2}{*}{$\frac{\mathrm{Cu}^{+}}{\operatorname{expt}}$} & \multirow{2}{*}{$\frac{\mathrm{Ag}^{+}}{\operatorname{expt}}$} & \multicolumn{2}{|c|}{$\mathrm{Li}^{+}$} & \multicolumn{2}{|c|}{$\mathrm{Na}^{+}$} \\
\hline & & & expt & theory & expt & theory \\
\hline 3 & 139 & 144 & 141 & 138 & 144 & 141 \\
\hline 4 & 167 & 170 & 166 & 166 & 171 & 168 \\
\hline 5 & 193 & 193 & 194 & 191 & 197 & 193 \\
\hline 6 & 218 & 215 & 217 & 215 & 221 & 216 \\
\hline 7 & 241 & 238 & 241 & 241 & 242 & 241 \\
\hline
\end{tabular}

of the oligomer, consistent with an increase in crosssection. Single peaks were observed for all oligomers at all temperatures $(80-300 \mathrm{~K})$, indicating that the $\mathrm{M}^{+} \mathrm{PS} n$ oligomers have single conformations. If multiple conformations, with cross-sections differing by $>5 \%$, were present, multiple peaks would have appeared in the ATDs $[22,26,31]$, unless their barriers to isomerization are less than $0.8 \mathrm{kcal} / \mathrm{mol}[26,32-34]$.

Collision cross-sections of the oligomer ions can be obtained from the ATDs and are given in Table 1. The cross-sections of each $n$-mer are similar for each metal cation, suggesting the conformations of $\mathrm{M}^{+} \mathrm{PSn}$ are similar for all four metal cations. However, slightly larger cross-section differences are observed for the smallest $\mathrm{M}^{+} \mathrm{PS} n$ oligomers. For example, the crosssection of $\mathrm{Ag}^{+}$PS3 is $\sim 3.5 \%$ larger than $\mathrm{Cu}^{+}$PS3 and $\mathrm{Na}^{+}$PS4 has a cross-section $\sim 3 \%$ larger than $\mathrm{Li}^{+}$PS4. For the larger oligomers (5-mer to 7-mer), the crosssections fall within the experimental error of $1-2 \%$.

\section{Theoretical Modeling}

Conformational identification of the ions is made by comparing the cross-sections of the lower energy theoretical structures (within $\sim 3 \mathrm{kcal} / \mathrm{mol}$ of the lowest energy structure) obtained from the scatter plots (see Figure 1) to the experimental cross-sections obtained from the ATDs. Unfortunately, the AMBER force field is not parameterized for $\mathrm{Cu}^{+}$and $\mathrm{Ag}^{+}$, only for $\mathrm{Li}^{+}$and $\mathrm{Na}^{+}$, and developing parameters for transition metals is not a trivial process. Transition metals can have significantly different metal-ligand binding properties than alkali metals, especially for interactions with $\pi$ systems because the transition metal can donate d electrons into the $\pi$ orbitals, and molecular mechanics calculations cannot easily model this behavior.

However, several experimental [35-40] and theoretical [41-43] studies on the binding of metal cations to benzene indicate the interaction is primarily electrostatic for both transition and alkali metals. (Although the calculations on transition metals did indicate that there was some donation of $\mathrm{d}$ electrons into the $\pi^{*}$ orbitals of benzene, the stabilities of the closed $\mathrm{d}$ shells in $\mathrm{Cu}^{+}$and $\mathrm{Ag}^{+}$reduced the amount of this donation [41].) Additionally, studies on the binding of metal cations to multiple benzenes $[35,37,39,40]$ have shown that alkali metals are sandwiched between the benzene rings in a similar manner as transition metals. There- fore, even though the theoretical modeling of $\mathrm{M}^{+} \mathrm{PSn}$ was only performed for $\mathrm{Li}^{+}$and $\mathrm{Na}^{+}$, the structures of $\mathrm{Cu}^{+} \mathrm{PS} n$ and $\mathrm{Ag}^{+} \mathrm{PS} n$ are not expected to be significantly different than those predicted for $\mathrm{Li}^{+} \mathrm{PSn}$ and $\mathrm{Na}^{+} \mathrm{PS} n$.

Figure 4 shows the lowest energy structure of the 150 calculated for the poly(styrene) 7-mer cationized by $\mathrm{Na}^{+}\left(\mathrm{Na}^{+}\right.$PS7). This structure is typical of all of the lowest energy structures, which have only minor conformational differences. The oligomer is predicted to be quasi-linear with the metal cation sandwiched between two phenyl groups near the middle of the oligomer chain. Similar low energy structures were also found for $\mathrm{Na}^{+}$PS3 to $\mathrm{Na}^{+}$PS6 and $\mathrm{Li}^{+}$PS3 to $\mathrm{Li}^{+}$PS7. The average cross-section of the lowest $\sim 3 \mathrm{kcal} / \mathrm{mol}$ structures, which are very similar to the structure shown in Figure 4 , are compared to the experimental values in Table 1. Agreement between experiment and theory is $\sim 1-2 \%$ for all of the modeled oligomers.

One slight difference between the $\mathrm{Li}^{+} \mathrm{PS}$ and $\mathrm{Na}^{+} \mathrm{PS}$ structures is that the larger $\mathrm{Na}^{+}$ion pushes the two "sandwiching" phenyl groups farther away than does $\mathrm{Li}^{+}$. The average distance between the metal cation and the central point within the neighboring phenyl group is $2.0 \AA$ for $\mathrm{Li}^{+}$and $2.4 \AA$ for $\mathrm{Na}^{+}$. Similar trends were observed in the metal-benzene studies. As the size of

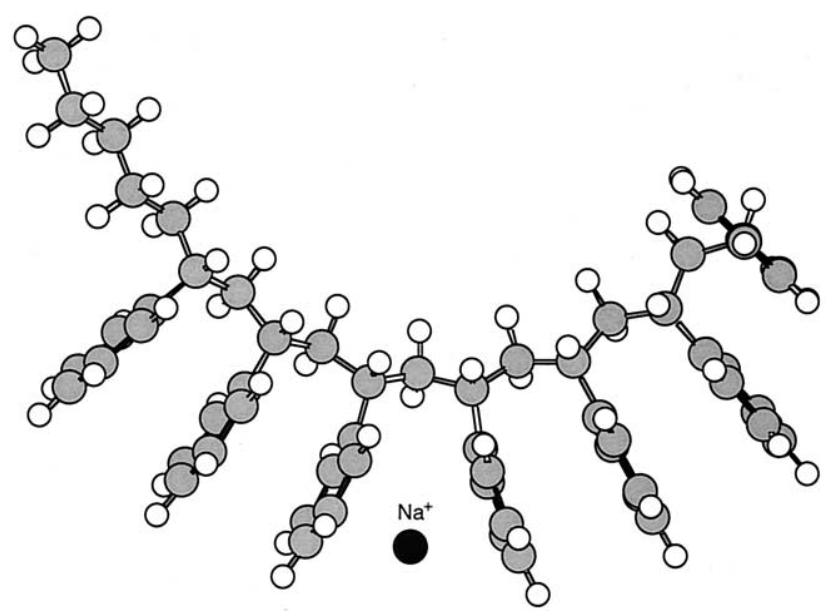

Figure 4. Lowest energy structure calculated for the poly(styrene) 7-mer cationized by sodium. Carbon atoms are gray, hydrogens are white, and the sodium cation is black. Similar structures were found for all of the modeled PS oligomers cationized by $\mathrm{Li}^{+}$ and $\mathrm{Na}^{+}$. 


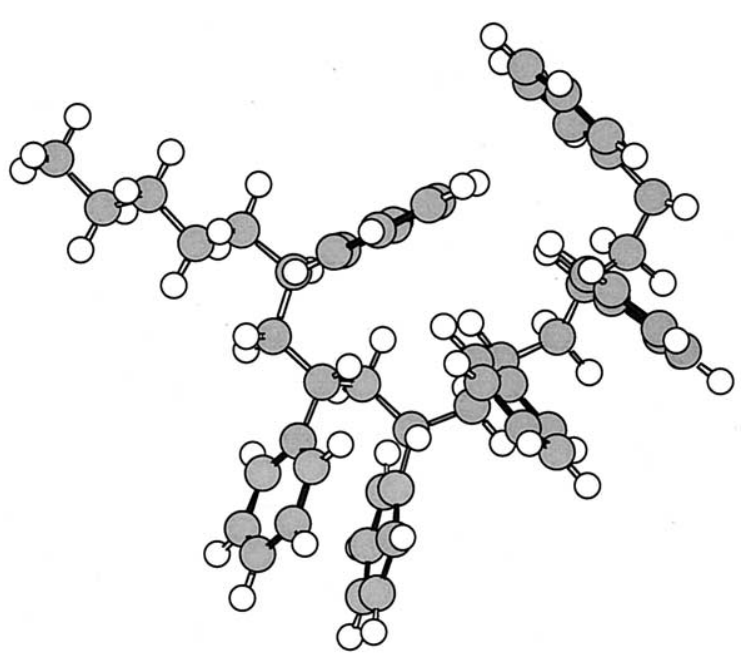

Figure 5. Lowest energy structure calculated for the poly(styrene) 6-mer. Carbon atoms are gray and hydrogens are white. The phenyl groups are more randomly oriented about the $-\mathrm{CH}-\mathrm{CH}_{2}-$ backbone than in the cationized species (see Figure 3).

the metal cation increased, the $\mathrm{M}^{+}$- benzene distance increased. For example, the $\mathrm{M}^{+}$-benzene distance was $1.9 \AA$ in $\mathrm{Li}^{+}\left(\mathrm{C}_{6} \mathrm{H}_{6}\right)$ and $3.4 \AA$ for $\mathrm{Cs}^{+}\left(\mathrm{C}_{6} \mathrm{H}_{6}\right)$ [39]. The total size of the $\mathrm{M}^{+} \mathrm{PS} n$ oligomers apparently outweighs this small structural difference, especially for larger values of $n$. The theoretical cross-section of $\mathrm{Na}^{+}$PS3 is $\sim 2.8 \%$ larger than $\mathrm{Li}^{+} \mathrm{PS} 3$, but the cross-section of $\mathrm{Na}^{+}$PS7 is the same as $\mathrm{Li}^{+}$PS7, a trend that tracks nicely with the experimental data.

One final comment about the theoretical structures of $\mathrm{M}^{+} \mathrm{PS} n$ concerns the relative positions of the phenyl groups. Commercial poly(styrene) is usually atactic [44], meaning the phenyl groups are randomly positioned on either side of the plane formed by the $-\mathrm{CH}_{2}-\mathrm{CH}-$ backbone. However, the calculations on $\mathrm{M}^{+} \mathrm{PS} n$ indicate that the $\mathrm{Li}^{+}$and $\mathrm{Na}^{+}$ions significantly influence the position of neighboring phenyl groups, aligning them on the same side of the backbone and making the oligomer isotactic (see Figure 4). The influence of metal cation can be seen more clearly by comparing the cationized poly(styrene) structures to the neutral ones (no cation attached). Figure 5 shows the lowest energy structure calculated for the neutral 6-mer (PS6). In this case, adjacent phenyl groups may stack, but they are not necessarily aligned with any of the other phenyl groups. The calculated cross-section of PS6 is $\sim 8 \%$ smaller than its cationized counterparts and thus an atactic structure is not present in the cationized systems since multiple peaks are not observed in the ATDs, even at $80 \mathrm{~K}$. In general, polymers that are isotactic are more likely to be crystalline (because of the regularity of the substitiuent groups) while atactic polymers are usually amorphous. Other physical properties of polymers, such as thermal stability and mechanical behavior, are also significantly affected by the tacticity of the polymer [44]. The presence of the metal cation forces two adjacent phenyl groups to be parallel, which

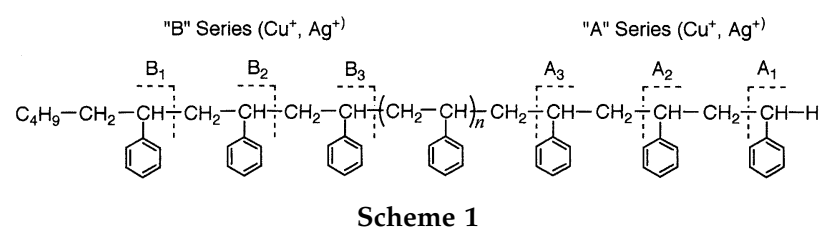

apparently catalyzes the formation of the isotactic form in these small oligomers.

\section{CID Spectra}

One goal of this study is to determine whether the conformations of cationized poly(styrene) oligomers can be used to help explain their CID spectra (similar to the $\mathrm{M}^{+}$PMMA study [18]). One problem is that the CID experiments used $\mathrm{Cu}^{+}$and $\mathrm{Ag}^{+}$as cationizing agents while the molecular modeling calculations used $\mathrm{Li}^{+}$ and $\mathrm{Na}^{+}$. However, the mass spectra and ion mobility results presented earlier indicate that the structures of $\mathrm{Cu}^{+} \mathrm{PS}$ and $\mathrm{Ag}^{+} \mathrm{PS}$ are not significantly different than those predicted for $\mathrm{Li}^{+} \mathrm{PS}$ and $\mathrm{Na}^{+} \mathrm{PS}$. This, combined with the published findings that alkali metals bind to benzenes in a structurally similar manner as transition metals, suggest that our results on $\mathrm{Li}^{+} \mathrm{PS}$ and $\mathrm{Na}^{+} \mathrm{PS}$ can be used to give relevant insight into the CID product distribution observed for $\mathrm{Cu}^{+} \mathrm{PS}$ and $\mathrm{Ag}^{+} \mathrm{PS}$.

The MALDI-CID spectra of poly(styrene) oligomers cationized by $\mathrm{Cu}^{+}$and $\mathrm{Ag}^{+}$have been published [7, 12, 14] and will not be shown here. The spectra are similar for both metals and show three distinct series of fragment ions that have low $\mathrm{m} / \mathrm{z}$ values ( 100-400) and retain the metal cation. Two of the three series appear to result from the direct cleavage of the oligomer backbone. These are shown in Scheme $\mathbf{1}$ and labeled the " $\mathrm{A}$ " and " $\mathrm{B}$ " series.

The number of " $\mathrm{A}$ " and " $\mathrm{B}$ " fragments observed in the MALDI-CID spectra of $\mathrm{M}^{+} \mathrm{PS} n$ varies with $n$. The largest $(\mathrm{m} / \mathrm{z})$ " $\mathrm{A}$ " and " $\mathrm{B}$ " fragments observed in the MALDI-CID of the 12-mer were $\mathrm{A}_{3}$ and $\mathrm{B}_{3}$. For the 26-mer, the largest " $\mathrm{A}$ " and " $\mathrm{B}$ " fragments observed were $\mathrm{A}_{5}$ and $\mathrm{B}_{5}$. For the 46-mer, the largest " $\mathrm{A}$ " and " $\mathrm{B}$ " fragments observed were $\mathrm{A}_{10}$ and $\mathrm{B}_{10}$. All of the " $\mathrm{A}$ " and " $\mathrm{B}$ " fragments retained the metal cation, but $\mathrm{A}_{1}$ and $\mathrm{B}_{1}$ fragments that did not retain the metal cation were also observed.

The third series of peaks observed in the CID spectra came at odd $\mathrm{m} / \mathrm{z}$ values, indicating they were formed by rearrangement reactions rather than by direct cleavages. The mechanism of formation is believed to be similar to that of immonium ions formed in the CID of peptides [14, $45]$ and they have the proposed structure [12, 14]

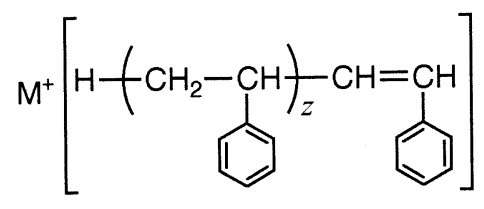




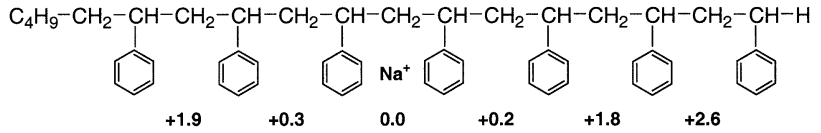

Figure 6. Schematic of the poly(styrene) 7 -mer cationized by sodium, showing the calculated change in energy $(\mathrm{kcal} / \mathrm{mol})$ of the structure as a function of the placement of the $\mathrm{Na}^{+}$cation. The lowest energy structure has $\mathrm{Na}^{+}$sandwiched between two phenyl groups near the middle of the chain (see Figure 4). When $\mathrm{Na}^{+}$is sandwiched near the ends of the oligomer, the resulting structure is predicted to be up to $2.6 \mathrm{kcal} / \mathrm{mol}$ higher in energy.

where $\mathrm{M}^{+}=\mathrm{Cu}^{+}, \mathrm{Ag}^{+}$and $z=0-2$.

Based on the structures of $\mathrm{M}^{+} \mathrm{PS} n$ shown in Figure 4, one question arises about the CID fragmentation shown in Scheme 1. If the metal cation is sandwiched between two phenyl groups near the middle of the oligomer chain, how does it end up on small " $\mathrm{A}$ " and "B" fragments at each end of the oligomer? The $\mathrm{M}^{+} \mathrm{PS} n$ oligomers are predicted to be slightly more stable with the $\mathrm{M}^{+}$cation near the middle of the chain. Figure 6 shows the calculated change in energy of $\mathrm{Na}^{+} \mathrm{PS} 7$ as a function of the position of $\mathrm{Na}^{+}$. When the $\mathrm{Na}^{+}$ion is near the ends of the chain, the resulting structure is $\sim 2-2.5 \mathrm{kcal} / \mathrm{mol}$ higher in energy than when $\mathrm{Na}^{+}$is near the middle of the chain. This difference may not be significant, but these results indicate that even if the metal cation is not near the middle of the chain it has an approximately equal chance of being anywhere along the chain (as long as it is sandwiched between two phenyl groups). There is no evidence that it prefers to be near the ends of the oligomer. Therefore, the formation of the cationized " $\mathrm{A}_{n}$ " and " $\mathrm{B}_{n}$ " fragments shown in Scheme 1 cannot be a result of one simple cleavage of the oligomer backbone, otherwise larger $\mathrm{A}_{n}$ and $\mathrm{B}_{n}$ fragments should have been observed. So why does the CID spectra of $\mathrm{M}^{+} \mathrm{PS} n$ only show cationized fragments exclusively from the ends of the oligomer? Why aren't larger $\mathrm{A}_{n}$ and $\mathrm{B}_{n}$ fragments observed?

One proposal is that the $\mathrm{M}^{+} \mathrm{PS}$ oligomer is initially cleaved randomly along the $-\mathrm{CH}_{2}-\mathrm{CH}-$ backbone, although the metal cation may induce a cleavage nearby, and then rapidly depolymerizes to the ends [12, 14, 46]. This mechanism was also proposed for the formation of " $\mathrm{A}$ " and " $\mathrm{B}$ " fragments in the CID of $\mathrm{M}^{+}$PMMA $[7,11]$. However, ion mobility and molecular modeling results suggested another possibility [18]. The study showed that the $\mathrm{M}^{+}$PMMA oligomers are U-shaped, with the metal cation exclusively bound to both ends of the oligomer. They also showed that the metal cations preferred to remain attached to larger MMA fragments. Depolymerization would be an energetically uphill battle. It was proposed, instead, that the $\mathrm{M}^{+} \mathrm{PMMA} n$ structure opened up upon collisional activation, leaving the metal cation attached to either end of the oligomer. The metal cation then cleaved the PMMA backbone nearby, resulting in small $\mathrm{A}_{1}-\mathrm{A}_{3}$ and $\mathrm{B}_{1}-\mathrm{B}_{3}$ fragments.

For $\mathrm{M}^{+} \mathrm{PS}$, however, a depolymerization scheme seems more likely. First of all, the $\mathrm{M}^{+} \mathrm{PS}$ oligomers are
Table 2. Calculated binding energies $(\mathrm{kcal} / \mathrm{mol})$ of $\mathrm{M}^{+}-\mathrm{PS} n$

\begin{tabular}{llc}
\hline$n$ & $\mathrm{Li}^{+}$ & $\mathrm{Na}^{+}$ \\
\hline \hline 3 & 29 & 18 \\
4 & 31 & 19 \\
5 & 33 & 21 \\
6 & 33 & 21 \\
7 & 32 & 21 \\
\hline
\end{tabular}

linear, not cyclic, so the $\mathrm{M}^{+}$cation could not possibly be attached to both ends of the oligomer. Second, as mentioned earlier, the calculations predict that the metal cation can be anywhere along the chain, with a slight preference for the middle. A single cleavage of the oligomer backbone should result in a larger distribution of " $\mathrm{A}$ " and " $\mathrm{B}$ " fragments. Third, there is no energetic preference for the metal cation to remain with larger PS fragments as in $\mathrm{M}^{+}$PMMA. Table 2 shows the calculated binding energies of $\mathrm{Li}^{+}$and $\mathrm{Na}^{+}$to PS oligomers of different lengths. The binding energies are essentially the same, regardless of oligomer size. This is probably due to the fact that the metal cation only interacts with two phenyl groups. Additional styrene units beyond the required two have little effect on the strength of the $\mathrm{M}^{+}$-PS interaction. (The fact that $\mathrm{M}^{+}$ interacts with two phenyl groups may also be the reason why $A_{1}$ and $B_{1}$ fragments, with only 1 phenyl group, that do not retain the metal cation are observed while larger $\mathrm{A}_{n}$ and $\mathrm{B}_{n}$ fragments are always cationized). Therefore, once the $\mathrm{M}^{+} \mathrm{PS}$ oligomer is initially cleaved, smaller $\mathrm{M}^{+} \mathrm{PS}$ fragments are predicted to be just as stable as the larger ones and the energy received upon collisional activation should be more than enough to induce successive depolymerization steps.

\section{Summary}

Ion mobility experiments and molecular modeling calculations were used to obtain information concerning the gas-phase conformations of poly(styrene) oligomers cationized by $\mathrm{Li}^{+}, \mathrm{Na}^{+}, \mathrm{Cu}^{+}$, and $\mathrm{Ag}^{+}\left(\mathrm{M}^{+} \mathrm{PS} n\right)$. Collision cross-sections measured for each $\mathrm{M}^{+} \mathrm{PS} n$-mer were found to be similar for all four metal cations, indicating the conformations and metal-oligomer binding properties are not significantly dependent on whether the metal cation is an alkali metal or transition metal. Molecular mechanics calculations predicted quasi-linear structures for $\mathrm{M}^{+} \mathrm{PS} n$ with the metal cation sandwiched between two phenyl groups, preferably near the middle of the chain. Cross-sections of these theoretical structures agreed well with experiment values $(\sim 1-2 \%$ difference). Calculated $\mathrm{M}^{+}$-PS binding energies did not significantly change with oligomer size because only two styrene units are needed to form a stable metaloligomer interaction. The phenyl groups in the cationized PS oligomers tended to align on the same side of the oligomer backbone, while those in the neutral species were more randomly oriented. The CID frag- 
mentation of $\mathrm{M}^{+} \mathrm{PS}$ is believed to involve random cleavage of the oligomer backbone, followed by rapid depolymerization. A similar mechanism was proposed for cationized poly(methyl methacrylate) oligomers, but ion mobility experiments and molecular modeling calculations indicated another possibility. For $\mathrm{M}^{+} \mathrm{PS}$, the conformations and energetics obtained in this study appear to be more consistent with a depolymerization scheme. Finally, the presence of the metal cation appears to transform the atactic neutral species into an ordered, isotactic structure with all the phenyl groups aligned, at least for the smaller sized oligomers studied here.

\section{Acknowledgments}

The support of the Air Force Office of Scientific Research under Grant F49620-99-1-0048 and ICI under SNF 2002 are gratefully acknowledged.

\section{References}

1. Nielen, M. W. F. Mass Spectrom. Rev. 1999, 18, 309.

2. Hanton, S. D. Chem. Rev. 2001, 101, 527.

3. Hillenkamp, F.; Karas, M.; Beavis, R. C.; Chait, B. T. Anal. Chem. 1991, 63, 1193A.

4. Bahr, U.; Deppe, A.; Karas, M.; Hillenkamp, F. Anal. Chem. 1992, 64, 2866.

5. Papayannopoulus, I. A. Mass Spectrom. Rev. 1995, 14, 12085.

6. McLuckey, S. A.; Habibi-Goudarzi, S. J. Am. Chem. Soc. 1993, 115, 12085.

7. Scrivens, J. H.; Jackson, A. T.; Yates, H. T.; Green, M. R.; Critchley, G.; Brown, J.; Bateman, R. H.; Bowers, M. T.; Gidden, J. Int. J. Mass Spectrom. Ion Process. 1997, 165/166, 363.

8. Przybilla, L.; Raeder, H.-J. K. Muellen,. Eur. Mass Spectrom. 1999, 5, 133.

9. Goldschmidt, R. J.; Wetzel, S. J.; Blair, W. R.; Guttman, C. M. J. Am. Soc. Mass Spectrom. 2000, 11, 1095.

10. Jackson, A. T.; Yates, H. T.; Scrivens, J. H.; Critchley, G.; Brown, J.; Green, M. R.; Bateman, R. H. Rapid Commun. Mass Spectrom. 1996, 10, 1668.

11. Jackson, A. T.; Yates, H. T.; Scrivens, J. H.; Green, M. R.; Bateman, R. H. J. Am. Soc. Mass Spectrom. 1997, 8, 1206.

12. Jackson, A. T.; Yates, H. T.; Scrivens, J. H.; Green, M. R.; Bateman, R. H. J. Am. Soc. Mass Spectrom. 1998, 9, 269.

13. Bottrill, A. R.; Giannakopulos, A. E.; Waterson, C.; Haddleton, D. M.; Lee, K. S.; Derrick, P. J. Anal. Chem. 1999, 71, 3637.

14. Jackson, A. T.; Bunn, A.; Hutchings, L. R.; Kiff, F. T.; Richards, R. W.; Williams, J.; Green, M. R.; Bateman, R. H. Polymer 2000, 41, 7437.

15. Pastor, S. J.; Wilkins, C. J. Int. J. Mass Spectrom. Ion Process. 1998, 175, 81

16. Bowers, M. T.; Kemper, P. R.; vonHelden, G.; vanKoppen, P. A. M. Science 1993, 260, 1446.

17. Clemmer, D. E.; Jarrold, M. F.; J. Mass Spectrom. 1997, 32, 577.
18. Gidden, J.; Jackson, A. T.; Scrivens, J. H.; Bowers, M. T. Int. J. Mass Spectrom. Ion Process. 1999, 188, 121.

19. Kemper, P. R.; Bowers, M. T. J. Am. Soc. Mass Spectrom. 1990, 1, 197.

20. vonHelden, G.; Wyttenbach, T. Bowers M. T. Int. J. Mass Spectrom. Ion Process. 1995, 146/147, 349.

21. Kemper, P. R.; Bowers, M. T. J. Phys. Chem. 1991, 95, 5134.

22. vonHelden, G.; Hsu, M.-T.; Gotts, N.; Bowers, M. T. J. Phys. Chem. 1993, 97, 8182.

23. Mason, E. A.; McDaniel, E. W. Transport Properties of Ions in Gases. Wiley: New York, 1988.

24. Pearlman, D. A.; Case, D. A.; Caldwell, J.; Seibel, G. L.; Singh, U. C.; Weiner, P.; Kollman, P. A. AMBER 4.0. University of California: San Francisco, CA, 1991.

25. Wyttenbach, T.; vonHelden, G.; Bowers, M. T. Int. J. Mass Spectrom. Ion Process. 1997, 165/166, 377.

26. Gidden, J.; Wyttenbach, T.; Batka, J. J.; Weis, P.; Jackson, A. T.; Scrivens, J. H. Bowers M. T. J. Am. Soc. Mass Spectrom. 1999, 10, 883.

27. Gidden, J.; Jackson, A. T.; Scrivens, J. H.; Bowers, M. T. J. Am. Chem. Soc. 2000, 122, 4692.

28. Wyttenbach, T.; vonHelden, G.; Batka, J. J.; Carlat, D.; Bowers, M. T. J. Am. Soc. Mass Spectrom. 1997, 8, 275.

29. Jackson, A. T.; Yates, H. T.; MacDonald, W. A.; Scrivens, J. H.; Critchley, G.; Brown, J.; Deery, M. J.; Jennings, K. R.; Brookes, C. J. J. Am. Soc. Mass Spectrom. 1997, 8, 132.

30. Dogruel, D.; Nelson, R. W.; Williams, P. Rapid Commun. Mass Spectrom. 1996, 10, 801.

31. vonHelden, G.; Gotts, N. G.; Palke, W. E.; Bowers, M. T. Int. J. Mass Spectrom. Ion Process. 1994, 138, 33.

32. Gidden, J.; Wyttenbach, T.; Batka, J. J.; Weis, P.; Jackson, A. T.; Scrivens, J. H.; Bowers, M. T. J. Am. Chem. Soc. 1999, 121, 1421.

33. Gidden, J.; Bushnell, J. E.; Bowers, M. T.; J. Am. Chem. Soc. 2001, 123, 5610.

34. Gidden, J.; Bowers M. T. (to be published).

35. Sunner, J.; Nishizawa, K.; Kebarle, P. J. Phys. Chem. 1981, 85, 1814.

36. Guo, B. C.; Purnell, J. W.; Castleman, A. W. Chem. Phys. Lett. 1990, 168, 155.

37. Kumpf, R. A.; Dougherty, D. A. Science 1993, 261, 1708.

38. Meyer, F.; Khan, F. A.; Armentrout, P. B. J. Am. Chem. Soc. 1995, 117, 9740.

39. Amicangelo, J. C.; Armentrout, P. B. J. Phys. Chem. A. 2000, 104, 11420.

40. Weis, P.; Kemper, P. R.; Bowers, M. T. J. Phys. Chem. A. 1997, 101, 8207.

41. Bauschlicher, J. W.; Partridge, H.; Langhoff, S. R. J. Phys. Chem. 1992, 96, 3273.

42. Nicholas, J. B.; Hay, B. P.; Dixon, D. A. J. Phys. Chem. A. 1999, 103, 1394.

43. Feller, D.; Dixon, D. A.; Nicholas, J. B. J. Phys. Chem. A. 2000, 104, 11414.

44. Fried, J. R. Polymer Science and Technology. Prentice Hall PTR: Upper Saddle River, 1995.

45. Ambihapathy, K.; Yalcin, T.; Leung, H. W.; Harrison, A. G. J. Mass Spectrom. 1997, 32, 209.

46. Craig, A. G.; Derrick, P. J. Aust. J. Chem. 1986, 39, 1421. 